\title{
NUEVAS TECNOLOGÍAS Y APRENDIZAJES ACERCA DE LA MODELACIÓN DEL CAPITAL CULTURAL Y LA VIDA ESCOLAR
}

\author{
María Valeria Álvarez * \\ Universidad Nacional de la Patagonia Austral, Argentina \\ ma_rez@hotmail.com \\ María Lourdes Villanueva ** \\ ma.lourdes.villanueva@gmail.com \\ Universidad Nacional de la Patagonia Austral, Argentina
}

Recibido: 10/06/2020 - Aceptado: 24/10/2020

Caminante, son tus huellas

el camino y nada más.

Caminante, no hay camino

se hace camino al andar.

Antonio Machado

\section{Resumen}

Proponemos pensar que la formación escolar, comprometida en una crisis, enfrenta un gran desafío frente a la expansión del uso de nuevas tecnologías, donde se reestructurarían los modos de la comunicación intersubjetiva. Las imágenes ganarían una nueva importancia relativa frente a formas más complejas de simbolización. Es posible sostener que desde edades tempranas las palabras cederían parte de su riqueza. Este proceso incidiría sobre las formas pedagógicas de construir un pensamiento complejo, y se presentaría como un nuevo rasgo generacional. El lenguaje escolar resultaría por tanto más lejano para los alumnos, e incluso también las prácticas producto de los hábitus profesionales de los docentes, ya que han sido modelados en otros contextos sociales y culturales. Entendemos desde esta mirada, que la reflexión pedagógica podría incorporar este nuevo rasgo del capital cultural socialmente construido como una atribución novedosa del alumnado, en tanto creemos fijan nuevos puntos de partida, y también posiblemente incida modelando otras mediaciones simbólicas que habilitan construir conocimiento. Tal vez habilidades que la escuela daba por supuestas en sus estudiantes, deberían ser paulatinamente desarrolladas en la escuela actualmente.

Palabras clave: Capital cultural - Nuevas tecnologías - Códigos - Escuela - Reflexión pedagógica.

\footnotetext{
* Profesora en Historia, estudiante avanzada de la Maestría en Ciencias Sociales, orientación Sociología, Universidad de Quilmes. Docente Adjunta - Área Historia Americana - Universidad Nacional de la Patagonia Austral, Unidad Académica Río Gallegos

** Doctora en la orientación en Ciencias Sociales y Humanas (UNLU) - Licenciada en Sociología. Profesora Adjunta Área Sociología, orientación General, Universidad Nacional de la Patagonia Austral, Unidad Académica Río Gallegos.
} 


\title{
NEW TECHNOLOGIES ANDA CULTURAL CAPITAL ABOUT THE MODELING OF CULTURAL CAPITAL AND SCHOOL LIFE
}

\begin{abstract}
We propose to think that school education, which is compromised in a crisis, faces a great challenge facing the expansion of the use of new technologies, where the modes of intersubjective communication would be restructured. Images would gain a new relative importance compared to more complex forms of symbolization. It is possible to maintain that from an early age words would give up part of their richness. This process would affect the pedagogical ways of building complex thinking and would present itself as a new generational feature. The school language would therefore be more distant for the students, and even the practices resulting from the professional habitus of the teachers, since they have been modeled in other social and cultural contexts. We understand from this point of view that pedagogical reflection could incorporate this new feature of socially constructed cultural capital as a new attribution of students, while we believe it sets new starting points and possibly it influences by modeling other symbolic mediations that enable the construction of knowledge. Perhaps skills that the school took for granted in its students should be gradually developed at school today.
\end{abstract}

Keywords: Cultural capital — New technologies - Codes - School - Pedagogical reflection.

\section{Introducción}

En línea con la propuesta conceptual de Pierre Bourdieu sobre la escuela como institución legitimadora de posiciones sociales, a través del otorgamiento de títulos escolares, proponemos indagar la articulación entre capital cultural legítimo y capital cultural familiar. Suponemos que el contacto de niños y adolescentes con nuevas tecnologías desde sus primeros años de vida alumbra procesos de transformación respecto al aprendizaje. Los nuevos escenarios pugnan por priorizar la imagen en su inmediatez y muchas veces el uso de estos aparatos es en gran medida táctil. Creemos que esto induce a modo de innovación un nuevo rasgo en el capital cultural de origen familiar.

Este proceso sucede en un escenario donde el capital cultural valioso -aquel que permite acceder a puestos de mayor calidad en el mundo productivo- se presenta más concentrado o, en palabras de Bourdieu (2000), cuya distribución transita por canales de mayor especificidad en su apropiación. Asimismo, a nivel ideológico, los crecientes niveles de desigualdad social son acompañados por un discurso donde se responsabiliza sólo al individuo por su trayectoria social, tanto por su desenvolvimiento en el mercado, y como veremos, también por su desempeño escolar. Desde la perspectiva del sociólogo francés ambas trayectorias están articuladas en tanto la formación adquirida desde plataformas institucionales prestigiosas sería más o menos valiosa para las demandas del mercado de trabajo, y por tanto también las remuneraciones relativas y condiciones de empleabilidad de los individuos.

Creemos que la pedagogía puede realizar un importante aporte en estos procesos, reconociendo a los nuevos sujetos pedagógicos, y algunas de sus singularidades. Esto, lejos del discurso que responsabiliza al individuo por su desempeño escolar -particularmente a sus condiciones naturales que lo favorecen o lo perjudican respecto al logro de ciertos resultados esperados-, captaría el modo en que las condiciones culturales actuales podrían incidir sobre la configuración de matrices cognitivas, permitiendo enlazar más satisfactoriamente esas condiciones subjetivas con la formación que la escuela ofrece. Al respecto, tal vez cabría revisar algunos supuestos en torno a capacidades que la escuela demanda tácitamente como necesarias para poder apropiarse de los contenidos escolares, y orientar el desarrollo gradual de esas capacidades los estudiantes en el marco de la vida escolar.

\section{La escuela}

En la perspectiva de Pierre Bourdieu la escuela es un campo relacional orientado al otorgamiento de títulos escolares, y entre cuyas misiones se halla la transmisión de capital cultural legítimo. Sin embargo, como bien observa Bourdieu, no todas las familias transmiten a sus hijos la misma complejidad en los usos del lenguaje, manejo de tecnologías y pautas de comportamiento. Por lo que, en la bifurcación resultante se generan posiciones periféricas y centrales en el acceso al capital cultural legítimo. Asimismo, es probable pensar que, 
ReVista de la Escuela de Ciencias de la EduCACIÓN, AÑo 17, NRO. 16, VOL. 1, ENERO A JUNIO de 2021. PÁGINAS 31-40. ISSN 2362-3349 (EN LínEA). NUEVAS TECNOLOGÍAS Y APRENDIZAJES ACERCA DE LA MODELACIÓN DEL CAPITAL CULTURAL Y LA VIDA ESCOLAR. MARÍA VALERIA ÁLVAREZ. MARÍA LOURDES VILLANUEVA.

en procesos de creciente desigualdad, esa brecha entre posiciones tiende a incrementarse, concentrándose en grupos más reducidos el capital cultural valioso para el mercado, cuya demanda se especifica y estratifica.

Esta legitimidad descansa en el respaldo estatal a través de currículos ocultos y explícitos a ciertas formas de comportase -normas-, el uso válido de ciertas herramientas y modos de expresarse, sobre otros modos socialmente disponibles. La posesión de ese capital cultural socialmente válido remite a la mayor exposición relativa que ciertos agentes -en tanto pertenecientes a determinados sectores sociales- han tenido desde sus primeros años de vida y durante su trayectoria vital. Es por tanto la familia un agente de socialización clave en este sentido.

Al respecto, pensar al proceso educativo incorporando también a la familia como agente socializador, requiere una historización breve, ya que en las últimas décadas la relación entre familia y escuela se habría modificado. El neoliberalismo, las nuevas formas organizacionales de las empresas y la penetración de las tecnologías de la información en el mundo productivo, han profundizado la segmentación del mercado laboral. En ese marco crece la desigualdad social desde la perspectiva de los ingresos obtenidos en el mercado, pero más aún, desde el acceso al capital cultural socialmente valioso (Bourdieu, 2000).

Esta segmentación del mercado laboral, también se traslada al sistema educativo. La escuela necesariamente tiene un destiempo en la formación transmitida en su adecuación respecto a las innovaciones en el mundo productivo. Pero también la mercantilización de crecientes esferas de la vida social en el marco del neoliberalismo afecta y modifica al sistema educativo. Se multiplican las escuelas privadas, que imponen en los montos de sus cuotas distintas restricciones a la entrada a familias y alumnos. Esto supone a su vez, un proceso de concentración del capital cultural valioso.

El conjunto de variables hace inestable al sistema educativo que enfrenta nuevas demandas, y está expuesto e inmerso en nuevas dinámicas internas y externas. Nos preguntamos si la formación docente ha podido incorporar la comprensión de la relación cualitativa entre esos elementos, en su formación profesional, brindando herramientas novedosas a los jóvenes egresados para intervenir sobre las mismas.

En tanto campo social e histórico, en la escuela se distribuyen posiciones también entre su personal. Docentes y directivos poseen titulaciones y antecedentes que respaldan la mayor o menor posesión relativa de ese capital cultural legítimo ${ }^{1}$. Transmiten enseñanzas a los alumnos, que al finalizar su ciclo escolar accederán a un título oficial. Este título respaldaba que sus detentores poseían saberes/habilidades específicas adquiridos a través de sus trayectorias educativas, y los habilitaba por tanto para realizar tareas específicas en el mercado laboral.

Sin embargo, las crecientes heterogeneidades del mercado laboral y la democratización en el acceso y obtención de esas credenciales educativas, les habrían quitado este lugar de principal variable explicativa para predecir posiciones ocupadas en el mercado laboral (Sendón, 2013). Al respecto, también los procesos de segmentación educativa darían cuenta de la valencia diferencial de los títulos otorgados, según las instituciones donde sus portadores se han formado.

\section{Las ideologías individualizadoras en la escuela}

La desigual apropiación del capital cultural legítimo presenta una fuerte tensión con la igualdad formal que la escuela representa en el imaginario moderno, entendida como un espacio de posibilidades homogéneas para toda la población. La escuela tiende a reproducir juicios sociales sin ser consciente de ellos, y por tanto presentando una tendencia hacia la reproducción de las desigualdades originales de clase (Bourdieu, 1991b).

En este marco "ser brillante" o lograr un nivel de desarrollo "pobre" esconderían así el grado familiar de cercanía o lejanía con este capital cultural institucionalizado de la escuela como organización. El autor francés proponía de este modo, atender al carácter tácito de gran parte de las destrezas y habilidades que la escuela exige, sin transmitirlas expresamente y dándolas por supuestas.

En el neoliberalismo la desigualdad social es revestida en el discurso político y social, y particularmente en el discurso escolar, por las nociones de "responsabilidad individual" y "meritocracia" propias del determinismo biologicista (Llomovate y Kaplan, 2005). Por tanto, al inscribirse en la naturaleza biológica son atribuciones inmodificables, y se desdibuja su carácter socialmente construido. Esta naturalización de la desigualdad formaría parte de los rasgos clásicos de una escuela que no fue abordada como sistema complejo y alejado del equilibro. En un contexto social dinámico, habitada por agentes sociales singulares, y penetrada por lógicas externas, la capacidad de la escuela para traducirlas a su propio lenguaje y otorgarles interpretaciones y tratamientos novedosos desde el campo pedagógico, muchas veces ha resultado limitada.

Al estudiar el sistema universitario francés indicaban Bourdieu y Passeron: "La ceguera ante las desigualdades sociales obliga y autoriza a explicar todas las desigualdades, especialmente en materia de éxito escolar, como desigualdades naturales, desigualdades de dotes" (Bourdieu y Passeron, 1973, p. 101).

Al respecto, detectar las desigualdades sociales que ingresan disfrazadas o transmutadas en la escuela, es una propuesta que aún mantiene un escaso interés por encontrar un relato que asuma el problema.

${ }^{1}$ Los docentes también habrían tenido, como sujetos habitantes del mundo social, diferentes posibilidades de acceso al capital cultural socialmente legitimado. 
ReVista de la Escuela de Ciencias de la EduCACIÓN, AÑo 17, NRO. 16, VOL. 1, ENERO A JUNIO de 2021. PÁGINAS 31-40. ISSN 2362-3349 (EN LínEA). NUEVAS TECNOLOGÍAS Y APRENDIZAJES ACERCA DE LA MODELACIÓN DEL CAPITAL CULTURAL Y LA VIDA ESCOLAR. MARÍA VALERIA ÁLVAREZ. MARÍA LOURDES VILLANUEVA.

Entendemos que poder situar a los alumnos en sus marcos de referencia sociales es una propuesta aún valiosa, en su carácter de subalterno respecto a la cultura dominante. Pasar por alto este abordaje significa una importante carencia de elementos que hablen de la desigualdad real en su mediación para apropiarse de los contenidos escolares.

\section{Nuevas tecnologías y capital cultural}

Particularmente, de acuerdo con el interés de este artículo, nos interesa atender un sentido, entre muchos otros posibles y muchos de ellos beneficiosos, en que las nuevas tecnologías también inciden sobre la vida escolar. Al respecto en el escenario de la globalización entendemos que la expansión en el uso de las nuevas tecnologías supone una importante problemática para andamiar nuevos saberes transmitidos en la escuela.

Al respecto, el acceso a nuevas tecnologías incidiría junto a otros factores en la modelación de matrices cognitivas primarias en los adolescentes, niñas y niños que habitan la escuela. En torno al capital cultural en estado incorporado indica Bourdieu:

Puede adquirirse en lo esencial, de manera totalmente encubierta e inconsciente, y queda marcado por sus condiciones primitivas de adquisición; no puede acumularse más allá de las condiciones de apropiación de un agente en particular; se debilita y muere con el portador... (Bourdieu, 1979, s/p).

Precisamente las posibilidades que tienen los alumnos de apropiarse de la formación transmitida por la escuela son desiguales. La configuración del marco cognitivo primario puede o bien entorpecer o bien facilitar las posibilidades de apropiarse de los contenidos escolares, de acuerdo a su grado de familiaridad relativa con los mismos.

En torno al sistema universitario francés, hace algunas décadas Bourdieu y Passeron observaban:

Cualquier clase de enseñanza, y en especial la enseñanza de la cultura -incluso de la cultura científica, presupone implícitamente un conjunto de saberes, un savoir-faire, y sobre una facilidad de expresión que son patrimonio de las clases cultas (Bourdieu y Passeron, 1973, p. 48)

Nuestro supuesto es que, en el escenario actual, al ser escasas las palabras que medien entre la imagen y su procesamiento en el infante y posiblemente también el adolescente, se induciría un estilo de lenguaje particular que se acompaña de un estilo de pensamiento de tipo más concreto que en generaciones previas.

Cabría aquí recuperar la distinción realizada por Bernstein entre "código restringido" y "código elaborado". De acuerdo con este autor las familias de sectores más humildes utilizan un lenguaje, más adherido a las circunstancias inmediatas, que dificulta expresar matices y situaciones individuales. Mientras las familias de sectores más favorecidos utilizan un lenguaje más amplio, que contempla una mayor variedad de opciones y que incluso permite elegir entre ellas. De este modo los códigos lingüísticos surgen vis a vis las condiciones sociales de constitución y adquisición.

Consideramos que Tedesco (1991) realiza una valiosa complejización al relacionar los aportes de Bourdieu y las perspectivas de Bernstein. El código restringido propio de familias humildes se distancia del código elaborado utilizado en la escuela y en las familias más favorecidas (Bernstein, 1975, p. 129; en Tedesco, 1991, p. 26). Ambos códigos lingüísticos dan cuenta de una trama de significaciones distintivas donde los mismos han sido gestados y que tienden a su vez a reforzar.

En este sentido indica Tedesco (1991):

El código actúa, en este sentido, con un carácter dialéctico: es expresión de estas relaciones y a su vez las determina. Su surgimiento está asociado al proceso de socialización en su conjunto, pero particularmente a cuatro órdenes de situaciones de intercambio lingüístico: situaciones de inculcación moral, de aprendizaje cognitivo, de imaginación o invención y de comunicación psicológica. (Tedesco, 1991, p. 26)

Al respecto, nuestra hipótesis es que la irrupción de las nuevas tecnologías tendería a afianzar un código de tipo restringido. La posibilidad de la imagen inmediata en el celular y en las computadoras, donde no median palabras, bien porque hay fotos, videos y hasta emoticones, tiende a poner en la imagen una carga de sentido que no se verbaliza. Suponemos que este proceso se estaría expandiendo a un sector importante de las capas sociales que han perdido en forma constante niveles de ingresos, introduciendo nuevos factores y demandas en los procesos de socialización. En esta tendencia también incidiría el comportamiento de la clase media en su elección escolar, junto al aumento de la desigualdad educativa, laboral y de distribución de la riqueza. 
ReVista de la Escuela de Ciencias de la EduCACIÓN, AÑo 17, NRO. 16, VOL. 1, ENERO A JUNIO de 2021. PÁGINAS 31-40. ISSN 2362-3349 (EN LínEA). NUEVAS TECNOLOGÍAS Y APRENDIZAJES ACERCA DE LA MODELACIÓN DEL CAPITAL CULTURAL Y LA VIDA ESCOLAR. MARÍA VALERIA ÁLVAREZ. MARÍA LOURDES VILLANUEVA.

En los meses de Aislamiento Social Preventivo y Obligatorio que Argentina está atravesando actualmente, parecen profundizarse las desigualdades presentes en el sistema escolar. En este contexto cobra cada vez mayor vigor el concepto de brecha digital:

[...] distancia "tecnológica" entre individuos, familias, empresas y áreas geográficas en sus oportunidades en el acceso a la información y a las tecnologías de la comunicación y en el uso de Internet para un amplio rango de actividades. Esa Brecha Digital se produce entre países y al interior de las naciones (Aladi, 2003, p. 13).

Pareciera que esta brecha es una variable interviniente y explicativa sobre las posibilidades desiguales de acceder a clases virtuales, realizar tareas solicitadas por los docentes, lecturas, entre otros.

\section{Revalorizando la palabra}

A fin de realizar esta aproximación consideramos valiosa la distinción realizada por Saussure (en Baz, 1999 y Alonso, 1998) entre lengua y habla. La lengua refiere de manera abstracta y sincrónica al sistema de signos creado socialmente, que es impuesto a los integrantes de la sociedad. El habla supone una aproximación diacrónica al modo en que los sujetos dan sentidos particulares a los signos polisémicos al referirse a sucesos concretos, en un contexto social y temporal determinado (Ortí, 1987 en Alonso, 1999) y por tanto, constituye la vehiculización de significados intersubjetivos. Por último, es a través de prácticas discursivas, de frases articuladas, que los sujetos expresan interpretaciones de hechos y procesos, de sí mismos y los otros, todos atravesados por significados colectivos.

Es por tanto posible suponer que la carga de significación depositada en las palabras usadas por niños y adolescentes, que cotidianamente conviven e interactúan con un importante bagaje de imágenes, tienda a adormecerse en su potencia para resignificar la cotidianeidad discursiva que le permite enmarcar la carga de imágenes. En torno a este proceso, cabe recuperar a la psicóloga María Beatriz Greco (2007), quien, revalorizando el lugar de la palabra, señala:

Gadamer dice que llevarse una palabra a la boca no es utilizar una herramienta, sino "situarse en una dirección de pensamiento que viene de lejos y nos desborda". "Pronunciar una palabra es situarse, entonces, en los rastros que trae y en los caminos que abre" (Larrosa, J y Kohan, W. 2003, p. 43), más que apropiarse de ella, es viajar con ella, o permitir que el pensamiento se desplace de idea en idea, de un sujeto a otro, de un tiempo o espacio a otro tiempo y espacio, de un texto a otro. (comillas dobles y citas de la autora) (Larrosa, J y Kohan, W. 2003, p. 43).

Justamente esta potencialidad es atravesada por los nuevos modos en que nos relacionamos con los sistemas en crisis mediados por las nuevas tecnologías. Podemos conocer la vida de otros, lugares geográficamente distantes o cercanos, por medio de fotos que lo retraten y de modo inmediato a nuestra inquietud. Es probable adelantar que los significados intersubjetivos que caracterizan las relaciones lingüísticas cotidianas y otras, que disponen segmentos importantes de las nuevas generaciones tendrían menos complejidad que en sus predecesoras.

Tal vez podríamos aventurar que el sentido común socialmente disponible -en tanto urdimbre simbólica al decir de Geertz-, desde donde se reflexiona, se interpreta y se decide cómo actuar en el mundo social, se estaría modificando al menos parcialmente. Probablemente este proceso se expanda por gran parte de las capas sociales, aunque los grupos sociales que ya estaban en posiciones menos ventajosas, hoy lo estén aún más.

En un sentido que creemos convergente, indica Bauman (2013) que el crecimiento en el uso del internet cuyo soporte son las nuevas tecnologías, también incide sobre maneras en que nos relacionamos. Indica el autor que la lógica del mundo online -donde pueden suprimirse contactos, darlos de baja ante un malentendido o enojo-, tiende a empobrecer de modo extendido nuestros modos de relacionarnos afectivamente, sobre todo ante los desacuerdos, dificultades y problemas. El autor reflexiona en torno a la temporalidad de las parejas, pero es posible pensar que este empobrecimiento de las herramientas emocionales comience a generar modificaciones en modos de resolver dificultades también en vínculos no amorosos.

En efecto, toda la historia de la era moderna puede ser relatada como la historia de una guerra declarada en contra de todos los malestares, los inconvenientes o los disgustos (...) Aunque hasta ahora ha sido parcial, la emigración masiva de hoy que viene desde el mundo offline hacia el recién descubierto territorio online, podría ser registrada dentro de dicha guerra como la más decisiva de las batallas. (Bauman, 2013, s/p, cursivas originales de la entrevista)

Por tanto, siguiendo Bernstein (1975, en Tedesco, 1991), suponemos que, según las innovaciones y su derrame interactivo podría acentuarse la distancia entre el código escolar, de tipo elaborado, y el capital cultural que portan estos alumnos. Es así que identificamos que, para una institución que ha incrementado su 
ReVista de la Escuela de Ciencias de la EduCACIÓN, AÑo 17, NRO. 16, VOL. 1, ENERO A JUNIO de 2021. PÁGINAS 31-40. ISSN 2362-3349 (EN LínEA). NUEVAS TECNOLOGÍAS Y APRENDIZAJES ACERCA DE LA MODELACIÓN DEL CAPITAL CULTURAL Y LA VIDA ESCOLAR. MARÍA VALERIA ÁLVAREZ. MARÍA LOURDES VILLANUEVA.

inestabilidad sistémica y se encamina a delimitar sus nuevos objetivos, existe un profundo desafío para la reflexión pedagógica, donde subyace tal vez un novedoso rasgo generacional.

\section{Desplazamientos en el sentido común}

Entendemos que las nuevas configuraciones sociales, particularmente asociadas a los modos en que las sociedades en que vivimos, inciden sobre los modos en que nos pensamos a nosotros mismos y a los otros, y a nuestras posibilidades vitales, inciden también sobre un proceso de reestructuración del sentido común (Castel, 2006b). Al respecto, cabe una vez más recuperar a Bourdieu (1991a):

Uno de los efectos fundamentales del acuerdo entre el sentido práctico y el sentido objetivado es la producción de un mundo de sentido común, cuya evidencia inmediata es redoblada por la objetividad que asegura el consenso sobre el sentido de las prácticas y del mundo, es decir, la armonización de las experiencias y el reforzamiento continuo que cada una de ellas recibe es la expresión individual o colectiva (en la fiesta, por ejemplo), improvisada o programada (lugares comunes, dichos) de experiencias semejantes o idénticas (p. 100; cursiva del autor).

Entre las discontinuidades del mundo objetivo, cabe señalar que el neoliberalismo se ha extendido en distintas partes del mundo desde fines del siglo XX. Allí se presenta un Estado neoliberal, donde instancias supranacionales inciden en el sentido de políticas públicas (Held, 1997) en beneficio del capital concentrado. Se genera un campo económico mundial, que debilita proyectos nacionales y desprotege a los ciudadanos (Bourdieu, 2002). Entre la tecnocracia prima nuevamente el individuo como responsable de su destino y se retractan muchas de las protecciones colectivas propias del Estado de Bienestar.

En las sociedades posindustriales se han incrementado los niveles de desigualdad social en varios sentidos. Esta tendencia retrotrae a varias décadas previas los mejores beneficios del bienestar.

Por el lado de los niveles de producción tienden a crecer los sectores de servicios y se reduce la incidencia de la industria en el conjunto. En ambos sectores es relativamente pequeño el número de trabajadores que domina las nuevas tecnologías -asociados a la programación y uso de software-, y por tanto son reducidos los sectores que logran estabilidad laboral y buenas remuneraciones. Mientras son amplios los contingentes tercerizados -que trabajan en aspectos periféricos del proceso productivo y lo hacen mientras lo justifica la demanda-, y también crecen los contratos a término o de tiempo parcial. Emergen nuevos sectores desempleados de forma permanente o transitoria, que son atendidos por políticas sociales focalizadas (Castel, 2006a). Al respecto numerosos autores observan una distancia creciente entre la demanda laboral -asociada al dominio de nuevas tecnologías- y el perfil de amplios grupos de la oferta laboral.

Con respecto a las consecuencias afectivas de las nuevas formas laborales, observa Sennett (2000), que tienden a empobrecerse los vínculos laborales asociados al trabajo. Antaño, en los puestos estables se compartía la vida cotidiana durante varias décadas, pero también los ciclos vitales con los compañeros de trabajo. Esto significaba vínculos de confianza, y de mutuo conocimiento. En el capitalismo flexible, orientado al consumidor prosperan los trabajos tercerizados y temporarios, que dificultan la construcción de vínculos estables y de compromiso con los otros.

En este contexto se dificulta construir un relato de identidad e historia vital, lazos sociales duraderos. ... "el capitalismo de corto plazo amenaza con corroer su carácter, en especial aquellos aspectos del carácter que unen a los seres humanos entre sí y brindan a cada uno de ellos una sensación de un yo sostenible" (Sennett, 2000, p. 25).

En este marco, cabría volver a pensar la génesis del capital cultural que dialécticamente se constituye en un entorno social que hipotetizamos muestra un bagaje de ofertas laborales repetitivas, rutinarias y tecnológicamente básicas para amplios sectores sociales.

En este contexto social, se fortalecen discursos ideológicos, prácticas sociales y políticas que se alejan de construir marcos explicatorios y comprensivos que se orienten a deconstruir la desigualdad. En este sentido Beck y Beck (2003) señalan:

...la desigualdad social está en aumento precisamente a causa de la difusión de la individualización...la individualización está convirtiéndose en la estructura social de la segunda sociedad moderna propiamente tal. El individuo institucionalizado (...) alude a la paradoja de una "estructura individualizadora" como proceso en curso no lineal, abierto y sumamente ambivalente (cursivas y comillas doble de los autores) (Beck y Beck, 2003, p. 31)

Precisamente, especifican estos sociólogos, el regreso al individuo, sucede en un contexto de creciente desigualdad social. En este marco son redefinidos los marcos identificatorios y regulatorios asociados a la clase, el género y la familia tradicional. La democratización se instala en los vínculos más íntimos, donde deben construirse acuerdos y tomarse decisiones en conjunto, siendo un contexto desafiante, pero con ausencia de las certezas de antaño. En palabras de los autores: 
ReVista de la Escuela de Ciencias de la EduCACIÓN, AÑo 17, NRO. 16, VOL. 1, ENERO A JUNIO de 2021. PÁGINAS 31-40. ISSN 2362-3349 (EN LínEA). NUEVAS TECNOLOGÍAS Y APRENDIZAJES ACERCA DE LA MODELACIÓN DEL CAPITAL CULTURAL Y LA VIDA ESCOLAR. MARÍA VALERIA ÁLVAREZ. MARÍA LOURDES VILLANUEVA.

La vida moderna está convirtiendo cualquier aspecto que se considere -la religión, la naturaleza, la verdad, la ciencia, la tecnología, la moral, el amor, el matrimonio, en "libertad precaria". Toda metafísica y trascendencia, toda necesidad y certidumbre está siendo sustituida por la habilidad personal (...) el rasgo distintivo de las modernas regulaciones o pautas es que, mucho más que en otros tiempos, deben ser suministradas por los individuos mismos, importadas a sus biografías mediante sus propias acciones. (comillas dobles de los autores) (Beck y Beck, 2003, pp. 38-39)

Particularmente en América Latina se observan niveles crecientes de exclusión y marginalidad que impactan de modo significativo en la apropiación y transmisión de la cultura, operando una posible "segmentación" de carácter estructural. En este sentido se fortalece también el peso de las escuelas privadas sobre el sistema educativo, y muchas veces una reducción en los gastos públicos, sobre todo de la inversión en educación, impactan sobre este deterioro.

El crecimiento de la informalidad en el mercado de trabajo, pareciera ser un rasgo importante de las actuales formas de la desigualdad. Al respecto, estudios realizados en sectores periféricos del Gran Buenos Aires, coincidiendo con hallazgos en otras zonas de Latinoamérica, indican que, en el sector no formalizado del mercado de trabajo, donde el Estado no regula las relaciones laborales ni incide sobre la resolución de los conflictos entre trabajadores o comerciantes, obliga a los individuos a resolverlos por sí mismos. En este marco muchas veces emerge la violencia como una forma de resolver desacuerdos o dificultades (Auyero y Berti, $2013)^{2}$.

La escuela se sitúa así en contextos más inciertos, donde nuevas dinámicas sociales posiblemente impacten modelando nuevas formas de reinscribir algunos aspectos del habitus de los sujetos y por tanto de su capital cultural. Sostenemos la hipótesis que, en este proceso, los sectores más desfavorecidos por la distribución de los ingresos, posiblemente transiten la escuela vía una desventaja aún mayor para hacerse acreedor a trayectorias escolares exitosas.

Al respecto pareciera ser necesario imaginar nuevos modos en que pueda emerger un paradigma educador que se ocupe de redefinir el "formato" escolar. Beltrán Llavador (1995) analiza la importancia que los formatos organizativos escolares tienen en la configuración de las subjetividades. Al respecto afirma "Por un lado, como organizaciones, permiten el ejercicio de una micro política que muestra la elaboración colectiva de sentido. Por otro, dada su peculiaridad escolar, hacen del intercambio de significados su objeto propio (...)". (Llavador, 1995, p. 97). Desde este punto de vista, consideramos de vital importancia el papel que la dimensión organizacional comporta para el desarrollo de perspectivas habilitadoras de sentidos, principios, estrategias y tecnologías en nuestras escuelas.

Numerosos estudios críticos de política educativa, fundamentalmente desarrollados durante los años '90 y principios de los 2000 (Bolívar, 1999; Frigerio, 1997; Paviglianiti, 1995; Tiramonti, 2001; Ruiz, 2005; entre otros), demuestran que la introducción de los principios de la reforma educativa neoliberal y su aplicación en las escuelas importaron cambios en el formato organizacional que en buena parte se yuxtapusieron con rasgos y prácticas del esquema previo caracterizados por su tradicional dimensión de racionalidad burocrática/instrumental. De este modo, los conceptos gerenciales de competencia, autonomía, eficiencia, flexibilidad -entre otros-, se impusieron en el discurso de la administración que, en la práctica, implantó un proceso creciente de regulación y centralización del orden escolar respondiendo en el fondo a la idea tradicional y burocrática de lo que entiende por escuela, y que implicó por ejemplo para el caso de los directivos, una sobrecarga de tareas administrativas y de control en desmedro de la tarea pedagógica. (Ruiz y Acconcia, 2012).

Podemos especular aquí, que la carencia de autonomía de las escuelas y las consecuencias desprofesionalizantes que ello supone en la toma de decisiones para las prácticas tanto pedagógicas como académicas y administrativas, se impone como un horizonte limitado que constriñe las posibilidades de los actores para idear formatos organizativos que alberguen alternativas innovadoras en cualquiera de sus dimensiones.

Aun así, existen experiencias alentadoras, como la de la Escuela Técnica Agropecuaria de Gobernador Gregores, en la provincia de Santa Cruz, que proporcionan ejemplos de miradas y acciones posibles para un formato escolar novedoso que articula e integra de manera adaptativa y flexible, los diferentes nodos que conforman la red organizativa. Un estudio de caso realizado por Ruiz y Acconcia (2012) sobre esta escuela demuestra que la finalidad pedagógico-productiva de la organización y la variedad de dimensiones y sectores

\footnotetext{
${ }^{2}$ A partir del estudio en un partido pobre del Gran Buenos Aires, Auyero y Berti (2013) sostienen la tesis que, al desplazarse el Estado de funciones sociales y económicas, los sujetos se ven obligados a resolver sus dificultades por sí mismos. Muchas veces la violencia física aparece como un recurso para resolver la vida cotidiana, saldar conflictos laborales en la economía informal, entre otros. Se asimilaría a una disposición que se incorpora de manera relacional. Por su parte, el Estado tiene un doble juego: aparece muchas veces como cómplice de la criminalidad, pero también puede operar de manera represiva. Se trataría de "una forma cualitativamente diferente de gubernamentalidad estatal" (Auyero y Berti, 2013, p. 122). Coincidiendo con análisis realizados en otros países, parece presentarse un "poder arbitrario del Estado y que refuerza la separación entre "poblaciones válidas e inválidas" (Rodgers, 2006; en Auyero y Berti; 2013, p. 122).
} 
que la componen (dirección burocrático-administrativa, laboratorio, campos y sectores de experimentación, aulas, albergue) constituyen "(...) una amalgama curiosa y poco común en los escenarios provinciales que conocemos, entre la dimensión burocrático-racional y la del ámbito de la profesionalidad." (Ruiz y Acconcia, 2012, p.165). Los autores consideran que se trata de un modelo heterodoxo de formato, que ejercita de manera permanente dispositivos, principios y criterios ad hoc visualizados necesarios en orden a los objetivos específicos de cada sector pero que resultan esenciales para el desarrollo del conjunto. En este sentido, caracterizan al diseño como "pulsátil" (en el sentido definido por Toffler, 1990) por su capacidad para estirarse y encogerse repetitivamente en función de las necesidades regulares y los emergentes, y por las posibilidades de proyectar variaciones y re-organizaciones. A modo de ejemplo citamos a Ruiz y Acconcia (2012):

(...) deviene en elemento básico de la configuración estructural de la escuela en la dimensión pedagógico-productiva el laboratorio, ámbito de los conocimientos fundados y experimentados, organizado, dirigido y puesto en marcha en relación con el conocimiento profesional del Veterinario, personal docente de la escuela. En esta parte del modelo, la malla, constelación o red presenta un diseño organizativo que posee rasgos o propiedades radiales que hace posible su articulación flexible, rítmica y dinámicamente fluida con los sectores/nodos pedagógico-productivos. (...) Si bien es dependiente funcional de la jerarquía burocrática, de hecho, adquiere un funcionamiento semiautónomo (...). (Ruiz y Acconcia, 2012, pp. 168-169):

No se puede dejar mencionar que la escuela del estudio se encuentra bastante alejada geográficamente del centro político decisorio en la provincia, situación que, según entendemos, la mantiene con cierto privilegiado distanciamiento del control político administrativo de la educación.

\section{La importancia de la reflexión pedagógica}

Creemos que los modos en que el neoliberalismo ha penetrado en los discursos escolares, desconociendo las circunstancias sociales en que los sujetos tienen trayectorias escolares discontinuas 0 truncas, es una limitante para revisar las prácticas escolares. Asociada a esta perspectiva, señalamos, tenemos un mundo escolar que gestiona su desequilibrio sistémico.

Al respecto entendemos que desde la investigación en el campo de la pedagogía podrían identificarse estos obstáculos en sus características típicas en tanto remiten a la pertenencia a grupos sociales; son colectivas $^{3}$, y esta identificación permitiría luego imaginar creativamente modos de operar sobre las mismas, a fines de favorecer la apropiación de capital cultural esperada en su trayectoria escolar.

Bourdieu en una entrevista realizada en 1991, observaba que la pedagogía tenía un gran potencial y un enorme desafío en favorecer la apropiación de la formación escolar en los sectores más desfavorecidos, reconociendo precisamente esos puntos de partida desiguales entre su alumnado, y por tanto modificando las prácticas pedagógicas de sus docentes. Esas condiciones desiguales, al ser construcciones culturales e históricas, era por tanto modificables.

Este autor agregaba la importancia del uso de un lenguaje adecuado para dirigirse al alumnado, que les permitiese advertir estos rasgos sociales e históricos de sus destrezas y particularmente de sus dificultades.

En este sentido, indican Bourdieu y Passeron (1973):

...una pedagogía verdaderamente racional, es decir, fundada sobre un estudio sociológico de las desigualdades culturales, contribuiría, sin duda, a aminorar las desigualdades ante la escuela y la cultura, pero no podría penetrar realmente en los hechos, sino se daban todas las condiciones de una democratización real en el reclutamiento de profesores y alumnos, para lo cual la instalación de una pedagogía racional sólo podría ser el comienzo (Bourdieu y Passeron, 1973, p. 101).

Nos animamos a sugerir que uno de los nudos críticos para la reflexión pedagógica radica precisamente en analizar cuánto de la carga de imagen tiende a relativizar la "presencia" o necesidad de lo discursivo en la arena cotidiana. Asimismo, como señala Gadamer, cuando los discursos brotan en los espacios de aprendizaje escolar, habría que pensar en qué se diferencian los rastros que portan respecto a los caminos que abren esos discursos. Al respecto, las características fuertemente segmentadas de mercado de trabajo, el crecimiento de la informalidad, las nuevas formas de los lazos sociales -entre otros- modelarían los "rastros" que permiten visualizar caminos a los estudiantes.

En otro sentido, aunque íntimamente vinculado a esta cuestión, encontramos la incidencia profunda de los formatos escolares, cuyos principios y dimensiones pueden limitar o habilitar las posibilidades de pensar, crear o imaginar alternativas que, como señalamos en el caso de la escuela agrotécnica, alberguen la capacidad de desplazarse y poner en marcha proyectos que ejerciten la re-organización democrática del diseño. La cuestión de la organización del trabajo continúa siendo un nudo crítico en tanto la administración (el aparato

\footnotetext{
${ }^{3} \mathrm{Si}$ se tratase de rasgos meramente individuales, no sería captable por una perspectiva más de tipo sociológica.
} 
ReVista de la Escuela de Ciencias de la EduCACIÓN, AÑo 17, NRO. 16, VOL. 1, ENERO A JUNIO de 2021. PÁGINAS 31-40. ISSN 2362-3349 (EN LínEA). NUEVAS TECNOLOGÍAS Y APRENDIZAJES ACERCA DE LA MODELACIÓN DEL CAPITAL CULTURAL Y LA VIDA ESCOLAR. MARÍA VALERIA ÁLVAREZ. MARÍA LOURDES VILLANUEVA.

público) continúe reforzando políticas de sobrerregulación, presentando restricciones de todo orden a la autonomía de los actores y las instituciones. El viejo modelo escolarizador portaba el peso de ser y devenir como posibilidad imaginada en el discurso y su conciencia en los agentes aún juega en el espacio de la innovación, que trastoca el formato o lo revela como un camino. Debemos considerar aquí que un papel no menor juega los supuestos pedagógicos que intervienen y modelan la vida escolar. Al respecto, el discurso pedagógico -como casi todas las ciencias sociales- ha mostrado muchas veces rasgos endogámicos, con poco espacio para otras explicaciones sobre las dinámicas que afectan y suceden en la escuela (Bolívar, 1999; Hargreaves, 1995; Molina et al, 2000; Popkewitz, 1994, entre otros). En este trabajo intentamos realizar un pequeño aporte en este sentido desde la sociología de Pierre Bourdieu y la política de la educación.

Finalmente, también debemos señalar que la brecha digital sigue siendo una deuda por saldar, que se reactualiza en nuestros días. Si los países de la región no pueden acercarse a los niveles cada vez mayores de producción de tecnología desplegados por las potencias, y se cristaliza su posición de meros consumidores de éstas, la desigualdad producida por el desarrollo diferencial del cambio tecnológico se sumará al conjunto de desigualdades preexistentes profundizando su reproducción y operando como una dimensión excluyente de los sujetos y las sociedades. Se trata de un debate que sigue vigente sobre la posibilidad de modificar tendencias laborales y educativas que excede las posibilidades reflexivas de este trabajo, aunque sin dudas creemos pone en relieve la deuda pendiente de democratizar este valioso capital cultural.

Es claro que la democratización de las oportunidades no sólo atañe a la escuela, pero ello no le quita valor a su aporte, a mediano y largo plazo, por su especificidad. Este aporte no es objeto de esta exploración, aunque quisimos acercarnos a la construcción del diagnóstico de una problemática que deviene central en la historia de la escuela, entre muchas otras miradas posibles sobre cómo se plasma la nueva clave que la formación escolar enfrenta.

\section{Referencias bibliográficas}

Alonso, L. E. (1998). La mirada cualitativa en sociología. Una aproximación interpretativa. España: Fundamentos.

Álvarez, M. V.; Michniuk, N. y Villanueva, M. L. (2012). Educación y Trabajo, miradas desde lo regional. Territorio y desigualdad de oportunidades. Buenos Aires: Ed. El Colectivo.

Asociación Latinoamericana de Integración - ALADI (2003). "La brecha digital y sus repercusiones en los países miembros de la ALADI". $\quad$ Montevideo. Disponible en: http://www.aladi.org/biblioteca/Publicaciones\%5CALADI\%5CSecretaria_General\%5CSEC_Estudios\%5C157Rev1. doc

Auyero, J. y M. F. Berti (2013). La violencia en los márgenes. Una maestra y un sociólogo en el conurbano bonaerense. Buenos Aires, Madrid: Katz.

Bauman, Z. (2013). "Educación sentimental en tiempos de internet: La más decisiva de las batallas". Entrevista publicada en Revista Arcadia, 9 de diciembre de 2013.2 Disponible en: https://www.revistaarcadia.com/impresa/especial/articulo/la-mas-decisiva-batallas-el-amor-tiempos-internetzygmunt-bauman/33198

Baz, M. (1999). La entrevista de investigación en el campo de la subjetividad. En: Jaidar, I. (comp.), Caleidoscopio de subjetividades, Universidad Autónoma Metropolitana-Xochimilco (Cuadernos tipi, 8), México, pp. 77-95.

Beck, U. y Beck-Gernsheim, E. (2003). Adiós a lo tradicional. La individualización y las libertades precarias. En: Ulrich, B. y Beck-Gernsheim, E. La individualización. El individualismo institucionalizado y sus consecuencias sociales y políticas, Barcelona: Paidós.

Beltrán Llavador, F. (1995). Tradición y cambio en la dirección escolar. En Frigerio, G. (comp.) De aquí y de allá. Textos sobre la Institución Educativa y su dirección. Buenos Aires: Kapelusz.

Bolívar. A. (1999). Cómo cambiar los centros educativos. España: Síntesis.

Bourdieu, P. (2002). Las estructuras sociales de la economía. Buenos Aires: Manantial.

Bourdieu, P. (2000). El sociólogo y las transformaciones recientes de la economía y la sociedad. Buenos Aires: Libros del Rojas.

Bourdieu, P. (1991a). El sentido práctico. Madrid: Taurus.

Bourdieu, P. (1991b). "La escuela según Pierre Bourdieu. Parte1". Entrevista. YouTube. Disponible en: https://www.youtube.com/watch?v=3mChkak7_3A .

Bourdieu, P. (1991b). "La escuela según Pierre Bourdieu. Parte 2". YouTube. Entrevista Disponible en: https://www.youtube.com/watch?v=uVb2w73dwH0 .

Bourdieu, P. (1979). Los Tres Estados del Capital Cultural. En: Revista Sociológica. Vol. 2. № 5. Otoño de 1987. Universidad Autónoma Metropolitana.

Bourdieu, P. y Passeron, J. C. (1973). Los estudiantes y la cultura. Buenos Aires: Ed. Labor.

Castel, R. (2006a). La metamorfosis de la cuestión social. Una crónica del asalariado. Buenos Aires: Ed. Paidós.

Castel, R (2006b). La sociología y la respuesta a la demanda social”, en Lahire, B., ¿Para qué sirve la sociología? Buenos Aires: Siglo Veintiuno Editores. Disponible en: https://filadd.com/doc/05-castel-r-la-sociologia-y-la-respuesta-a-la

Frigerio, G. (1997). Políticas, instituciones y actores en educación. Buenos Aires: Novedades Educativas.

Greco, M. B (2007). La autoridad (Pedagógica) en Cuestión. Una crítica al concepto de autoridad en tiempos de transformación. Buenos Aires: Homo Sapiens.

Hargreaves, A. (1995). Profesorado, cultura y posmodernidad. Madrid: Morata.

Held, D. (1997). La democracia y el orden global. Del Estado Moderno al gobierno cosmopolita. Barcelona: Ed. Paidós.

Llomovate, S. y Kaplan, C. (2005). Desigualdad educativa. La naturaleza como pretexto. Buenos Aires: Noveduc.

Molina, F. et. al (2000). Reforma educativa, cultura y política. Buenos Aires: Temas. 


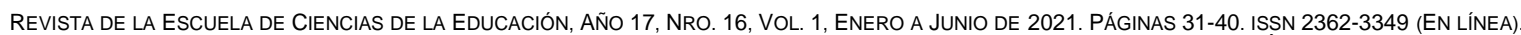
NUEVAS TECNOLOGÍAS Y APRENDIZAJES ACERCA DE LA MODELACIÓN DEL CAPITAL CULTURAL Y LA VIDA ESCOLAR. MARÍA VALERIA ALVAREZ. MARÍA LOURDES VILLANUEVA.

Paviglianiti, N. (1995). La ley federal como elemento de regulación de la realidad socioeconómica argentina. La Plata. Facultad de Humanidades y Ciencias de la Educación - UNLP.

Popkewitz, T. (1994). Sociología política de las Reformas Escolares. Madrid: Morata.

Ruiz et. al (2005). Autonomía educativa bajo nuevos principios de estructuración provincial en los '90. En: Revista Espacios Nueva Serie. Año IV, $\mathrm{n}^{\circ} 4$.

Ruiz, J. y Acconcia, M. L. (2012). La escuela técnica agropecuaria de Gobernador Gregores (Santa Cruz). Un enfoque organizativo heterodoxo. En: Álvarez, M. V.; Michniuk, N. y Villanueva, M. L. Educación y Trabajo, miradas desde lo regional. Territorio y desigualdad de oportunidades. Buenos Aires: El Colectivo.

Sendón, M. A. (2013). Dossier. En: Educación y trabajo: Consideraciones actuales en torno al debate del papel de la educación". En Propuesta Educativa. Número 40 - Año 22 - nov. 2013 - Vol. 2 - FLACSO. Buenos Aires, pp. 8$31 \mathrm{http}: / /$ propuestaeducativa.flacso.org.ar/wp-content/uploads/2019/12/40-dossier-sendon.pdf

Sennett, R. (2000). La corrosión del carácter. Las consecuencias personales del trabajo en el nuevo capitalismo. Barcelona: Anagrama.

Tedesco, J. C. (1991). Conceptos de sociología de la Educación. Centro Editor de América Latina. Selección (conceptos de "Capital cultural", "modelo" y "socialización").

Tiramonti, G. (2001). Modernización educativa de los '90. Buenos Aires: Temas.

Toffler, A. (1990). El cambio de poder. Conocimientos, bienestar y violencia en el umbral del siglo XXI. Barcelona: Plaza \& Janés. 